\title{
Development of CSMM-Based Shell Element for Reinforced Concrete Structures
}

\author{
C. H. Luu' ${ }^{1}$, Y. L. Mo' ${ }^{1}$ Thomas T. C. Hsu ${ }^{1}$ \\ ${ }^{1}$ Department of Civil and Environmental Engineering, University of Houston, 4800 Calhoun, Houston, \\ 77204, USA
}

\section{ABSTRACT}

Reinforced concrete shell structures have been widely used in a variety of modern engineering applications. It is found from earthquake reconnaissance that reinforced concrete (RC) shell structures, such as nuclear containments, cooling towers, roof domes, shear walls, etc., are the key elements in resisting earthquake disturbances. This paper presents the development of a finite element analysis (FEA) program, SCS-3D, to predict the inelastic behavior of RC shell structures. In the program, a Cyclic Softened Membrane Model (CSMM)-based shell element is developed based on the degenerated shell theory with a layered approach and taking into account the CSMM developed at the University of Houston. To form the FEA program, the constitutive relation modules and the analysis procedure were implemented into a finite element program development framework, OpenSees developed at UC Berkeley. Several large-scale structural tests were employed to validate the developed FEA program, including RC panels subjected to a combination of shear and bending, three-dimensional RC shear wall and cylindrical RC tanks subjected to reversed cyclic loading.

Keywords: reinforced concrete, shell element, constitutive model, nonlinear finite element 


\section{INTRODUCTION}

Due to the high strength-to-weight ratio and the efficient load-carrying capacity, the reinforced concrete $(\mathrm{RC})$ shell structures have been widely used in a variety of modern engineering applications, such as pressure vessels, water tanks, cooling towers, arch dams roof domes and varieties of containers [1]. The reserved cyclic behavior of RC shell structures is very difficult to predict, especially when they are subjected to the earthquake loading. It is because the seismic response of the RC shell structures is highly nonlinear, which is caused by highly inelastic behavior of materials including rebars and concrete under-reversed cyclic actions. However, from the structural point of view, a whole RC shell structure can be visualized as an assembly of many RC elements. This concept makes it easier for the analysis of the complex structure, in which the finite element analysis combined with proper constitutive models for concrete and reinforcing bars could be a very powerful tool. The key to rational analysis of the RC structure is to completely understand the behavior of one element isolated from the structure. Once a rational model is developed to predict the behavior of one element, this rational model can then be incorporated into a finite element program to predict the behavior of the whole structure under different kinds of loading.

Since the 1970's, many researchers have proposed an analytical model to predict the behavior of RC shell structures using the finite element method. The main approach used by most researchers is to develop a reinforced concrete shell element by combining a rational constitutive model of reinforced concrete material into finite element formulations of a general shell element with layer approaches (Hand, Pecknold [2]; Cervera, Hinton [3]; 
Scordelis and Chan [4]; Hu and Schnobrich [5]; Polak and Vecchio [6]; Kim, Lee [7]; Zhang, Bradford [8]; Lee [9]; Xiang, Mo [10]; Gopinath, Iyer [11], Matešan, Radnić [12], Hrynyk and Vecchio [13], and Lu, Xie [14]). The main problem faced by most researchers in the analysis of RC shell structures using the finite element method was that it often required expensive computational time due to the complicated material models and the difficulties encountered in the stability and accuracy of the solutions. Some material models for reinforced concrete material such as fracture mechanics or detail crack localizations were successfully verified at the element level but faced a numerical problem when applied at the structure level, which requires a large number of elements. It is found from the above researches that a selection of appropriate material models, which provides adequate accuracy with reasonable computational time, plays an important role in the success of the analysis of the RC shell structures using the finite element method.

In recent years, the "smeared-crack" concept has been widely used in the analysis of RC structures. This concept allows internally cracked reinforced concrete composite to be treated as a simple, continuous material rather than a complicated, discontinuous composite [15]. The advantage of this simplification is that mechanics-based analysis can be applied to predict the behavior of the RC shell structures regardless of cracking. To implement this simplification, the material constitutive models must be based on the smeared (averaged) stress and strain relationship of the internally cracked RC elements. Since the 1980's, studies of the constitutive material of reinforced concrete based on the "smeared-crack" concept have been carried out by many researchers; however, an experimental study of shell elements 
could only be carried out by a few research groups $[16,17]$. Using the experimental results of panel tests, many constitutive models for RC have been proposed. The models are the Compression-Field Theory and Modified Compression Field Theory by Vecchio and Collins [18]; Disturbed Stress Field Theory by Vecchio [19]; Rotating-Angle Softened Truss Model (RA-STM) [20, 21]; Fixed-Angle Softened Truss Model (FA-STM) [22], the Softened Membrane Model (SMM) [23] and the Cyclic Softened Membrane Model (CSMM) [24]. Among these constitutive models, the CSMM is the most versatile and accurate, as shown in Figure 1. It is capable of rationally predicting the cyclic shear behavior of reinforced concrete membrane elements including the stiffness, ultimate strength, descending branch, ductility and energy dissipation capacity. The model is even extended to study the behavior of steel plate ultra high-performance concrete structures [25].

Following the success of the membrane element development [26], the present study accomplishes three main tasks: (1) to formulate the CSMM for the development of a shell element, called CSMM-based shell element, in the finite element program, (2) to implement the developed CSMM-based shell element into a finite element program SCS-3D, using OpenSees as a framework and (3) to validate the finite element program SCS-3D by comparing its predictions with the experimental results of several large-scale structural tests including RC panels subjected a combination of shear and bending, three-dimensional RC shear wall, and cylindrical RC tanks subjected to reversed cyclic loading.

\section{RESEARCH SIGNIFICANCE}

The development of a finite element program for reinforced concrete structures includes 
three components, namely modeling, formulation and implementation. In this paper, the Cyclic Softened Membrane Model (CSMM) [24] is adopted for the simulation of reinforced concrete shell-type structures. The major contributions of this study are the formulation and the implementation, which resulted in a finite element program called Simulation of Three Dimensional Concrete Structures (SCS-3D). The CSMM-based shell element implemented in the finite element program SCS-3D can predict accurately the hysteretic loops of three dimensional RC shell structures subjected to seismic loading.

\section{FINITE ELEMENT FORMULATION}

The CSMM-based shell element is developed by utilizing the formulation of an 8-node Serendipity curved shell element [27] with a multi-layer approach [4] accompanying with the Cyclic Softened Membrane Model (CSMM) [24]. The Serendipity shell element has a total of eight nodes with five degrees of freedom (DOF) at each node, three translational DOFs, and two rotational DOFs. The idea of creating this element arose from the difficulty of solving the ill-conditioned equations that occurred in the 3D solid element when the dimension in the thickness direction was small [27]. The Serendipity shape function is applied to all DOFs. The element showed excellent performance when applied to the cases of moderate thick shell structures by using the normal integration rule $(3 \times 3)$. The degenerated curved shell element with the layered approach has been recognized as one of the most promising methods for analysis of RC shell-type structures since the 1970's [28]. By using the degenerated curved shell element with the layered approach, the behavior of RC shell structures can be captured directly from cyclic stress-strain relationships of the materials, and no phenomenological rule 
is needed [5]. The element is based on the Reissner-Mindlin theory, which only requires $\mathrm{C}^{0}$ continuity in the shape function for assuring complete inter-element deformation compatibility and can model the behavior of reinforced concrete shells with significant transverse shear deformation. The elements are derived from the equations of three-dimensional continuum mechanics by reducing their dimensions in the thickness direction [29]. The overview of several key attributes of the shell element is presented in this section; however, detailed presentation of the finite element formulation is available elsewhere [30].

\subsection{Element Assumptions}

The derivation of the element is based on three assumptions. First, the stress normal to the mid-surface, $\sigma_{z}$, is small compared with the other stress components and is negligible. This assumption implies that there is no deformation along the thickness of the element. Second, after the element deforms, a straight fiber of the element, which was previously perpendicular to the undeformed middle surface, still needs to remain straight but doesn't need to be perpendicular to the deformed middle surface. This assumption is similar to the Mindlin theory assumption for plates, in which the transverse shear strains $\gamma_{x z}$ and $\gamma_{y z}$ exist and are uniformly distributed along the thickness direction of the shell element, as shown in Figure 2. Third, the out-of-plane shear behavior is assumed to be independent of the in-plane behavior. This assumption allows CSMM to be implemented to the stiffness matrix of the shell element as a plane stress material. 


\subsection{Coordinate Systems}

\subsubsection{Coordinate systems for the shell element}

Coordinate systems are used to define global geometry, nodal coordinates and nodal displacements, stiffness matrices and applied force vectors of the shell element. There is a total of four coordinate systems used in the finite element formulation of the proposed CSMM-based shell element. These coordinate systems include the global coordinate system $(X, Y, Z)$, the nodal coordinate system $\left(V_{1 i}, V_{2 i}, V_{3 i}\right)$, the curvilinear coordinate system $(\xi, \eta, \zeta)$ and local coordinate system $(x, y, z)$ as shown in Figure 3. The nodal coordinate system is specified by three vectors, $V_{1 i}, V_{2 i}$, and $V_{3 i}$, defined at the node $\mathrm{i}$ of the shell element. Vector $V_{3 i}$ is called "normal" vector and is perpendicular to the middle surface of the shell element.

\subsubsection{Coordinate systems for CSMM}

Three Cartesian coordinates, $x-y, 1-2$, and $x_{s i}-y_{s i}$, are defined for each layer of the reinforced concrete shell elements, as demonstrated in Figure 4. Coordinate $x-y$ defines the local coordinate. Coordinate 1-2 represents the principal stress directions of the applied stresses that have an angle $\theta_{1}$ with respect to the $x$-axis. Steel bars can be oriented in different directions in the rebar layer. Coordinate $x_{s i}-y_{s i}$ indicates the direction of the $\mathrm{i}^{\text {th }}$ group of rebars, where the $\mathrm{i}^{\text {th }}$ group of rebars is located in the direction of axis $x_{s i}$ with an angle $\theta_{s i}$ to the $x$-axis.

\subsection{Geometry}

The global coordinate of an arbitrary point inside the shell element is determined by the interpolation of the global coordinates and the direction cosines of the normal vectors of all 
nodes of the element using shape functions by Eq. (1).

$$
\left\{\begin{array}{l}
X \\
Y \\
Z
\end{array}\right\}=\sum N_{i}(\xi, \eta)\left\{\begin{array}{l}
X_{i} \\
Y_{i} \\
Z_{i}
\end{array}\right\}+\sum N_{i}(\xi, \eta) \zeta \frac{t_{i}}{2}\left\{\begin{array}{c}
l_{3 i} \\
m_{3 i} \\
n_{3 i}
\end{array}\right\}
$$

where $N_{i}(\xi, \eta)$ is a two-dimension shape function at node $\mathrm{i}, t_{i}$ is the thickness at node $i$ of the shell element and $l_{3 i}, m_{3 i}$, and $n_{3 i}$ are the direction cosines of the normal vector $V_{3 i}$ corresponding to the global coordinate system.

\subsection{Displacements}

The displacements of an arbitrary point inside the shell element are computed by the interpolation of the displacements and rotations of all nodes of the element using shape functions. The displacements correspond to the global coordinate system and are expressed by the following equation:

$$
\left\{\begin{array}{l}
\mathrm{u}_{X} \\
\mathrm{u}_{Y} \\
\mathrm{u}_{Z}
\end{array}\right\}=\sum N_{i}(\xi, \eta)\left(\left[\begin{array}{l}
\mathrm{u}_{X i} \\
\mathrm{u}_{Y i} \\
\mathrm{u}_{Z i}
\end{array}\right]+\zeta \frac{t_{i}}{2}\left[\begin{array}{cc}
-l_{2 i} & l_{1 i} \\
-m_{2 i} & m_{1 i} \\
-n_{2 i} & n_{1 i}
\end{array}\right]\left\{\begin{array}{c}
\alpha_{i} \\
\beta_{i}
\end{array}\right\}\right)
$$

where $u_{X i}, u_{Y i}$, and $u_{Z i}$ are the global displacements and $\alpha_{i}$, and $\beta_{i}$ are the rotations with respect to the nodal coordinates at node $i$ of the shell element, respectively, as shown in Figure 5 [29].

\subsection{Strain and Displacement Relationship}

For small displacement problems, the strains are taken as the first-order derivative of displacements. The strain-displacement relationship is expressed by the following equations:

$$
\varepsilon_{X}=\frac{\partial u_{X}}{\partial X}, \varepsilon_{Y}=\frac{\partial u_{Y}}{\partial Y}, \varepsilon_{Z}=\frac{\partial u_{Z}}{\partial Z}, \varepsilon_{X Y}=\frac{\partial u_{X}}{\partial Y}+\frac{\partial u_{Y}}{\partial X}, \varepsilon_{X Z}=\frac{\partial u_{X}}{\partial Z}+\frac{\partial u_{Z}}{\partial X}, \varepsilon_{Y Z}=\frac{\partial u_{Y}}{\partial Z}+\frac{\partial u_{Z}}{\partial Y}
$$




\subsection{Numerical Integration and Layer Approach}

Numerical integration can be used to evaluate the element stiffness matrix, the internal force vector, and the stress resultants of the shell element [28]. For the stress resultants, the numerical integration can be performed along the thickness direction by using the layered approach, as shown in Figure 6. The layered approach is computationally expensive; however, it is more accurate for nonlinear material such as reinforced concrete in which the material properties (and stress) are discontinuous functions of $\zeta$. As shown in Figure 6, along the thickness of the element, the strains are linear functions of $\zeta$ and the stresses are nonlinear functions of $\zeta$.

Based on the layered approach, the equations to evaluate the stress resultants (Figure 7) are expressed as follows:

$$
\begin{aligned}
& N_{x}=\frac{t}{2} \sum_{i=1}^{n} \sigma_{x}^{i} \Delta \zeta^{i}, \quad N_{y}=\frac{t}{2} \sum_{i=1}^{n} \sigma_{y}^{i} \Delta \zeta^{i}, \quad N_{x y}=\frac{t}{2} \sum_{i=1}^{n} \tau_{x y}^{i} \Delta \zeta^{i}, \\
& M_{x}=-\frac{t^{2}}{4} \sum_{i=1}^{n} \sigma_{x}^{i} \zeta^{i} \Delta \zeta^{i}, \quad M_{y}=-\frac{t^{2}}{4} \sum_{i=1}^{n} \sigma_{y}^{i} \zeta^{i} \Delta \zeta^{i}, M_{x y}=-\frac{t^{2}}{4} \sum_{i=1}^{n} \tau_{x y}^{i} \zeta^{i} \Delta \zeta^{i}, \\
& Q_{x}=\frac{t}{2} \sum_{i=1}^{n} \tau_{x z}^{i} \Delta \zeta^{i}, \quad Q_{y}=\frac{t}{2} \sum_{i=1}^{n} \tau_{y z}^{i} \Delta \zeta^{i},
\end{aligned}
$$

where $\mathrm{n}$ is the number of layers.

The integration to evaluate the element stiffness matrix and the internal force vector can be divided into two processes. The first process is to perform the integration along the thickness direction by using the layered approach. The constitutive material matrix $[\mathbf{D}]$, the strain-displacement matrix $[\mathbf{B}]$ and the Jacobian matrix $[\mathbf{J}]$ vary through thickness direction and are functions of $(\xi, \eta, \zeta)$. The second process is to perform the integration on the middle 
surface of the element by using Gaussian quadrature rules. The normal full integration rule that consists of $3 \times 3$ Gauss points can be applied.

The equations to evaluate the element stiffness matrix and the internal force vector based on the Gaussian quadrature rules and the layered approach are expressed in the following equations:

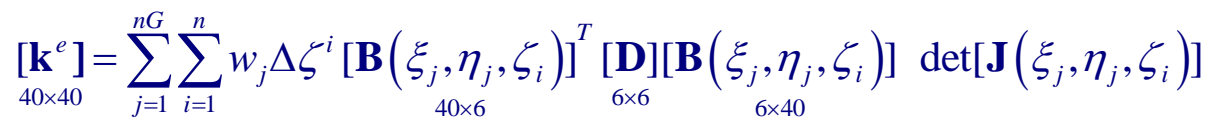

$$
\begin{aligned}
& \left.\underset{40 \times 1}{\left\{\mathbf{f}^{e}\right.}\right\}=\sum_{j=1}^{n G} \sum_{i=1}^{n} w_{j} \Delta \zeta^{i}\left[\mathbf{B}\left(\xi_{j}, \eta_{j}, \zeta_{i}\right)\right]^{T}\{\underset{6 \times 1}{\{\sigma}\} \operatorname{det}\left[\mathbf{J}\left(\xi_{j}, \eta_{j}, \zeta_{i}\right)\right]
\end{aligned}
$$

where $\mathrm{nG}$ is the number of Gauss points, and $w_{j}$ is the weight function. The values of $\xi_{j}, \eta_{j}$ and $w_{j}$ are given elsewhere [30].

\subsection{Material Constitutive Matrix}

In the layered approach, the section of the shell element is divided into several layers throughout the thickness. The strains at each layer are assumed to be uniform and interpolated by the shape function from the displacements at nodes of the element. For each layer of the shell element, the local material matrix [D], given in Eq. (7), is a 6 x 6 matrix and corresponds to six independent strains $\left(\varepsilon_{x}, \varepsilon_{y}, \varepsilon_{z}, \gamma_{x y}, \gamma_{y z}, \gamma_{x z}\right)$ given in the local coordinate system $(x, y, z)$, including the in-plane and the out-of-plane strains. The relationship between stresses and strains in each layer for both steel and concrete is expressed as 


$$
\left\{\begin{array}{c}
\sigma_{x} \\
\sigma_{y} \\
\tau_{x y} \\
\sigma_{z} \\
\tau_{x z} \\
\tau_{y z}
\end{array}\right\}=\left[\begin{array}{cccccc} 
& & & 0 & 0 & 0 \\
& \overline{\mathbf{D}}_{i n} & 0 & 0 & 0 \\
& & 0 & 0 & 0 \\
0 & 0 & 0 & 0 & 0 & 0 \\
0 & 0 & 0 & 0 & {\left[\overline{\mathbf{D}}_{\text {out }}\right.}
\end{array}\right]\left\{\begin{array}{c}
\varepsilon_{x} \\
\varepsilon_{y} \\
\gamma_{x y} \\
\varepsilon_{z} \\
\gamma_{x z} \\
\gamma_{y z}
\end{array}\right\}
$$

where $\left[\overline{\mathrm{D}}_{\text {in }}\right]$ and $\left[\overline{\mathrm{D}}_{\text {out }}\right]$ are in-plane and out-of-plane tangential material matrices, respectively.

Because the strain in the direction perpendicular to the mid-surface of the shell element $\varepsilon_{z}$ is considered, the coefficients in the fourth column and the fourth row of the material matrix are assumed to be zero to ensure that the normal stress $\sigma_{z}$ equals zero. Based on the assumptions of the element, the in-plane and out-of-plane responses are calculated independently. Each layer is assumed to be in a state-of-plane stress. Hence, Eq. (9) is assumed to be the combination of the following equations:

For in-plane behavior

$$
\left\{\begin{array}{l}
\sigma_{x} \\
\sigma_{y} \\
\tau_{x y}
\end{array}\right\}=\left[\begin{array}{l}
\overline{\mathbf{D}}_{i n} \\
\end{array}\right]\left\{\begin{array}{c}
\varepsilon_{x} \\
\varepsilon_{y} \\
\gamma_{x y}
\end{array}\right\}
$$

For out-of-plane behavior

$$
\left\{\begin{array}{l}
\tau_{x z} \\
\tau_{y z}
\end{array}\right\}=\left[\overline{\mathrm{D}}_{\text {out }}\right]\left\{\begin{array}{l}
\gamma_{x z} \\
\gamma_{y z}
\end{array}\right\}
$$

\subsubsection{Material constitutive matrix for in-plane behavior}

The in-plane tangent material constitutive matrix $\left[\bar{D}_{i n}\right]$ for a reinforced concrete element was formulated in Mo, Zhong [26] and is expressed as follows:

For a concrete layer 


$$
\left[\bar{D}_{i n}\right]=\left[T\left(\theta_{1}\right)\right]^{-T}\left[\overline{D_{c}}\right][V]\left[T\left(\theta_{1}\right)\right]
$$

For an embedded reinforcement layer

$$
\left[\bar{D}_{i n}\right]=\sum_{i}\left[T\left(\theta_{s i}\right)\right]^{-T}\left[\bar{D}_{s i}\right]\left[T\left(\theta_{s i}-\theta_{1}\right)\right][V]\left[T\left(\theta_{1}\right)\right]
$$

where $\left[\bar{D}_{c}\right]$ and $\left[\bar{D}_{s i}\right]$ are the uniaxial tangential stiffness matrix of concrete and embedded reinforcement, respectively. The derivations of $\left[\bar{D}_{c}\right]$ and $\left[\bar{D}_{s i}\right]$ are the same as the RC membrane element [31], and are expressed as follows:

The uniaxial constitutive matrix of concrete $\left[\bar{D}_{c}\right]$ is given by

$$
\left[\overline{D_{c}}\right]=\left[\begin{array}{ccc}
\bar{E}_{1}^{c} & \partial \sigma_{1}^{c} / \partial \bar{\varepsilon}_{2} & 0 \\
\partial \sigma_{2}^{c} / \partial \bar{\varepsilon}_{1} & \bar{E}_{2}^{c} & 0 \\
0 & 0 & G_{12}^{c}
\end{array}\right]
$$

where $\bar{E}_{1}^{c}$ and $\bar{E}_{2}^{c}$ are the tangential uniaxial moduli of concrete in the 1 and 2 directions, respectively, evaluated at a certain stress/strain state. The off-diagonal terms $\partial \sigma_{1}^{c} / \partial \bar{\varepsilon}_{2}$ and $\partial \sigma_{2}^{c} / \partial \bar{\varepsilon}_{1}$ are obtained by using the uniaxial constitutive relationships and take into account the state of the concrete stresses and uniaxial strains in the 1-2 directions, which are not zero because the stress and strain of the concrete in compression is softened by the orthogonal tensile strains. $G_{12}^{c}$ is the shear modulus of concrete, taken as $\left(\sigma_{2}^{c}-\sigma_{1}^{c}\right) / 2\left(\varepsilon_{2}-\varepsilon_{1}\right)$

The uniaxial stiffness matrix of steel bars $\left[\bar{D}_{s i}\right]$ is evaluated as

$$
\left[\overline{D_{s i}}\right]=\left[\begin{array}{ccc}
\rho_{s i} \bar{E}_{s i} & 0 & 0 \\
0 & 0 & 0 \\
0 & 0 & 0
\end{array}\right]
$$

where $\bar{E}_{s i}$ is the uniaxial tangential modulus for the rebars embedded in concrete, which is determined for a particular stress/strain state. 


\subsubsection{Material matrix for out-of-plane behavior}

In this shell element, the out-of-plane action is only taken by concrete. For simplicity, the relationship between the out-of-plane shear stresses and the out-of-plane shear strains is assumed to be linear. The out-of-plane shear stiffness matrix, including the constant coefficient is expressed as

$$
\left[\overline{D_{\text {out }}}\right]=k_{s}\left[\begin{array}{cc}
\bar{G}_{x z} & 0 \\
0 & \bar{G}_{y z}
\end{array}\right]
$$

where $\bar{G}_{x z}=\bar{G}_{y z}=\bar{G}_{c}=0.5 \bar{E}_{c} /(1+v), \quad \bar{E}_{c}$ is the tangential modulus of concrete, taken as $3875 \sqrt{\mathrm{f}_{c}^{\prime}(\mathrm{MPa})}$ [15]; $\boldsymbol{V}$ is the Poisson ratio of concrete, taken as 0.2 and $k_{s}$ is the shear correction factor, taken as 5/6 [32].

\section{CONSTITUTIVE MODELS}

The constitutive models used in the CSMM-based shell element were based on the Cyclic Softened Membrane Model (CSMM) proposed by Mansour and Hsu [24] (Figure 1). The CSMM is capable of accurately predicting the pinching effect, the shear ductility and the energy dissipation capacities of RC members. The CSMM includes the cyclic uniaxial constitutive relationships of concrete and embedded mild steel. The characteristics of the concrete constitutive laws include: (1) the softening effect on the concrete in compression due to the tensile strain in the perpendicular direction; (2) the softening effect on the concrete in compression under reversed cyclic loading; (3) the opening and closing of cracks, which are taken into account in the unloading and reloading stages. The characteristics of embedded mild steel bars include: (1) the smeared yield stress is lower than the yield stress of bare steel bars and the hardening ratio of steel bars after yielding is calculated from the steel ratio, steel 
strength and concrete strength; (2) the unloading and reloading stress-strain curves of embedded steel bars take into account the Bauschinger effect. The details of the constitutive models can be referred to references $[15,24]$.

\section{ANALYSIS PROCEDURE}

An analysis procedure was developed to perform nonlinear analyses of RC shell structures using the developed CSMM-based shell element. A flow chart for the analysis solutions under load increment is described in Figure 8. Throughout the procedures, the material matrix $[\bar{D}]$ is determined first, and the local stiffness matrix $\left[\mathrm{k}^{e}\right]$ and the local resisting force increment vector $\{\Delta \mathrm{f}\}$ are calculated. Then, the global stiffness matrix $[\mathrm{K}]$ and global resisting force increment vector $\{\Delta \mathrm{F}\}$ are assembled. In each iteration, the local material matrix $[\overline{\mathrm{D}}]$, the local stiffness matrix $\left[\mathrm{k}^{e}\right]$ and the global stiffness matrix $[\mathrm{K}]$ are iteratively refined until a convergence criterion is achieved.

In the analysis, for establishing the constitutive material matrix at each layer of the CSMM-based shell element, the principal stress direction $\theta_{1}$ can be evaluated at the cracking loading step and is maintained during the analysis, as shown in Figure 8. Before cracking, it is assumed that the principal stress coincides with the principal strain; therefore, the angle $\theta_{1}$ can be computed from the local in-plane cracking strains as well. Once the principal stress direction $\theta_{1}$ is defined, the local material matrix $\left[\overline{\mathrm{D}}_{\text {layer }}\right]$ can be obtained at each layer of the shell element. The procedure for the calculation of the global element stiffness and global resisting force of the shell elements is outlined by the outer white block in Figure 8. 
This algorithm shows the simple analysis procedure of RC shell structures using a load increment. The procedure can be incorporated with other static integrators such as displacement control for different kinds of nonlinear finite element analysis. The solution procedure in the algorithm uses the Newton-Raphson method with Krylov acceleration technology [33]. The constitutive material matrix $[\bar{D}]$, the element tangent stiffness matrix $\left[k^{e}\right]$ and the global stiffness matrix $[K]$ are calculated in each iteration.

\section{IMPLEMENTATION}

OpenSees stands for Open System for Earthquake Engineering Simulation [34]. OpenSees has been developed in the Pacific Earthquake Engineering Center (PEER), and is an object-oriented framework for simulation applications in earthquake engineering using finite element methods. An object-oriented framework is a set of cooperating classes that can be used to generate software for a specific class of problems, such as finite element analysis. The framework dictates an overall program structure by defining the abstract classes, their responsibilities and how these classes interact. OpenSees is a communication mechanism for exchanging and building upon research accomplishments, and has the potential for a community code for earthquake engineering because it is an open source.

In this study, new classes that represent the proposed element and material are implemented into the OpenSees framework to create a finite element analysis program named SCS-3D (Simulation of Concrete Structures). This program can perform nonlinear finite element analysis of reinforced concrete shell structures under static, reversed cyclic and dynamic loading. Figure 9 presents all of the classes employed for the CSMM-based shell 
element in this study. Two UniaxialMaterial modules for concrete (ConcreteZ01) and steel (SteelZ01) were created previously based on the uniaxial constitutive relationship of concrete and steel in CSMM [31]. In this study, the proposed 8-node CSMM-based shell element, so-called CSMMShellS8, was implemented into OpenSees. The element has six degrees of freedoms (DOFs) at each node, in which, three DOFs represent the displacements, two DOFs represent rotations, and one DOF is a drilling degree for freedom based on drilling theory. The NDMaterial module, so-called CSMMLayer, was created to incorporate the formulation of the tangential material matrix for concrete and steel into each layer of the developed shell element.

The implementation of the developed modules into OpenSees is shown in Figure 9. The Analysis and Recorder objects are omitted in this figure. The CSMMLayer is implemented with the CSMMShellS8 element to represent the CSMM-based shell element. The CSMMLayer is related with the two UniaxialMaterial modules, SteelZ01 and ConcreteZ01, to determine the material constitutive matrix and to calculate the stress of the elements at each layer.

\section{VALIDATIONS}

Several correlation studies were conducted to verify the accuracy of the CSMM-based shell element developed in the study. The structures selected for validations included panels tested under pure bending and a combination of shear and bending [6], a three-dimensional RC cylindrical tank [32] and a RC shear wall [35]. All structures were tested until failure under either monotonic or reverse cyclic loading. 


\subsection{Shear Panels Tested Under Combined Out-of-Plane Bending and In-Plane Shear}

The developed shell element was also verified by tests on four panels subjected to combined out-of-plane bending moment and in-plane shear. The tests were performed by Polak and Vecchio [6] at the University of Toronto, Toronto, Canada. All four panels had the same dimensions of $1625 \times 1625 \times 316 \mathrm{~mm}$. However, the orientations of steel in the panels were different. Panels SM1, SM2, and SM3 were reinforced by steel bars of $0^{\circ}$ angles, and panel SM4 was reinforced by steel bars of $45^{\circ}$ angles. The angles are between the steel bar orientation and the direction of the principal tensile stress. Material properties and loading schemes of the specimens are given in Table 1. Each panel had different compressive concrete strength; however, the properties of reinforcement were similar. All four panels were reinforced with $1.25 \%$ and $0.42 \%$ steel per layer in the $x$ - and $y$-directions, respectively. The yielding strength of the steel bars in the $x$ - and $y$-directions was $425 \mathrm{MPa}$ and $430 \mathrm{MPa}$, respectively. As shown in Table 1, four different loading schemes were used in the experimental program. Panels SM1 and SM3 were subjected to pure uniform out-of-plane bending moment, in which one-way moment was applied to SM1 along the horizontal direction and two-way moments were applied to panel SM3 in both horizontal and vertical direction with a moment ratio of 3.2. Panels SM2 and SM4 were subjected to a combination of uniform out-of-plane moment and uniform in-plane shear.

The finite element meshes of the four panels are illustrated in Figure 10. In the model, a total of 16 CSMMShellS8 elements was utilized for each panel. Because the model was expected to also simulate the bending behavior, many concrete layers should be used to 
capture the variation of stress along the cross-section of the element. Ten layers of concrete and two layers of steel were assigned for each element using the CSMMLayer material module. The figures also showed the constraints and loads applied to each element. To simulate the out-of-plane bending condition, uniform moments were applied along the edges of each element. To simulate the in-plane shear condition, constraints and loads were assigned so that the element was subjected to uniform tensile stress in the horizontal direction and uniform compressive stress in the vertical direction simultaneously. The analyses were performed by a predetermined displacement control scheme. The common displacement increment used in the analyses was $0.01 \mathrm{~mm}$. The KrylovNewton method was used as the solution algorithm. The nodal displacement and corresponding horizontal forces were recorded at each converged displacement step, and the stress and strain of the elements were monitored.

The analytical moments versus curvatures of the four panels obtained from the finite element analysis were compared with the experimental results, as shown in Figure 11. The analytical and experimental results were illustrated by solid and dotted curves, respectively. In general, the analytical results are shown to have a good agreement with the experimental outcomes. Table 2 provides the comparison of the analytical and experimental results regarding the cracking, yielding and ultimate moments the RC panels. In general, all the predicted and experimental values match quite well. The mean of the test-to-analysis ratio of the cracking moments is 0.99 with a coefficient of variation $(\mathrm{COV})$ of 0.06 . The mean of the test-to-analysis ratio of the yielding moments is 1.04 with a coefficient of variation $(\mathrm{COV})$ of 
0.02. The mean of the test-to-analysis ratio of the ultimate moments is 1.01 with a coefficient of variation $(\mathrm{COV})$ of 0.03 .

\subsection{RC Cylindrical Tank Tested Under Reserved Cyclic Loading}

The scaled reinforced concrete (RC) tank specimen tested by Harada, Onituka [36] was selected to validate the capacity of the developed CSMM-based shell element in predicting the structural behavior of cylindrical RC structures under the reserved cyclic loading. The tank had a dimension of $2.0 \mathrm{~m}$ net height and a $1.8 \mathrm{~m}$ radius (centerline dimension). The outer and inner diameters of the tank were $3.1 \mathrm{~m}$ and $2.9 \mathrm{~m}$, respectively. The thickness of the tank was $0.1 \mathrm{~m}$. The specimen was reinforced with $0.8 \%$ reinforcement ratios equally in both the vertical and circumferential directions. The details of dimensions and material properties of the specimen are summarized in Table 3. The average compressive strength of concrete used for the specimen was $28 \mathrm{MPa}$. The nominal yielding strength of both the vertical and circumferential reinforcements was $384 \mathrm{MPa}$ and $410 \mathrm{MPa}$, respectively. The specimen was fixed at the bottom by steel rods that connected the specimen with a rigid plate foundation. The horizontal cyclic load was applied by three actuators, one with the capacity of $3000 \mathrm{kN}$ and the others with the capacity of $500 \mathrm{kN}$ each. No axial load was applied to the specimen. The cyclic load was transferred through a steel ring located on the top of the specimen. Bolt connections fixed the steel ring along the perimeter of the specimen. This test configuration allowed the loads to be uniformly distributed to the specimen [32].

A finite element analysis was carried out on the specimen. The specimen was modeled by the finite element mesh, as shown in Figure 12. The tank was modeled by 30 CSMMShellS8 
elements, which were the CSMM-based shell element developed in this study. Ten layers of concrete and two layers of steel were assigned for each element using the CSMMLayer material module. All elements were assigned with $0.8 \%$ of reinforcement. The steel layers were defined at the exact locations of steel at the cross-section of each element. The other ten RigidShellS8 elements, which are elastic 8-node shell elements with very high stiffness, are defined at the top of the model to simulate the rigid connection. All nodes at the bottom of the model were constrained to not allow any translations or rotations. Uniformly distributed horizontal loads were applied at all nodes along the perimeter at the top of the specimen. The analysis was performed by a predetermined displacement control scheme. The common displacement increment used in the analysis was $0.5 \mathrm{~mm}$. The KrylovNewton method was used as the solution algorithm. The nodal displacements and corresponding horizontal forces were recorded at each converged displacement step, and the stress and strain of the elements were monitored.

The analytical horizontal force versus displacement relationships of the specimen obtained from the analysis were compared with the experimental results, as shown in Figure 13. The analytical and experimental results are illustrated by a solid curve and a dotted curve, respectively. Table 4 provides the comparison of the analytical and experimental results regarding the loads and displacements at peak loads of the RC tank. The analytical results provide a good correlation with the experimental outcomes. The analytical model accurately predicted the whole load-deformation curve, especially the starting point of the descending part. The accuracy of the predictions are very good except that the stiffness right after 
cracking is higher than the test outcomes. The difference may result from the boundary condition, in which the use of the rigid shell elements in the analytical model may not accurately simulate the effect of the steel ring on the top of the specimen. Overall, the primary backbone curve, the peak strength, the descending branch and the failure characteristic of the analytical result matched closely with the experimental data. Furthermore, the analytical model also accurately predicted the unloading path and the pinching effect of the cylindrical tank.

\subsection{Three-Dimensional RC Shear Wall Tested Under Reserved Cyclic Loading}

The developed program was further validated by modeling a 3D reinforced concrete (RC) shear wall tested by Palermo and Vecchio [35] at the University of Toronto, Toronto, Canada. The dimensions of each of the top and bottom slabs were 4415 x 4000 x $460 \mathrm{~mm}$. The main components contained two parts: a web wall $2020 \mathrm{~mm}$ high and $75 \mathrm{~mm}$ thick and each of the two flange walls that were $2020 \mathrm{~mm}$ high and $95 \mathrm{~mm}$ thick. Two layers of D6 (diameter of 6 $\mathrm{mm}$ ) reinforcing bars were provided vertically and horizontally within the specimen. The spacings of the D6 reinforcing bars in the web wall were $140 \mathrm{~mm}$ and $130 \mathrm{~mm}$ in the horizontal and vertical directions, respectively. Similarly, the spacing of $140 \mathrm{~mm}$ of D6 reinforcing bars was also used in the two flange walls in the horizontal direction. The arrangement of the D6 reinforcing bars in the vertical reinforcement of the two flange walls, however, was divided into two regions. The inner region, adjacent to the web wall, was reinforced with spacing of $140 \mathrm{~mm}$, and the outer region, near the tip of the flanges, was reinforced with the spacing of $355 \mathrm{~mm}$. The amount of reinforcement and material properties 
of the specimen are summarized in Table 5. The average compressive strength of concrete used for the specimen was 21.7 MPa. The nominal yielding strength of $605 \mathrm{MPa}$ was used for reinforcement in both longitudinal and transverse directions. In the test setup of the specimen, the bottom slab was fixed to the laboratory strong floor to simulate a rigid foundation. An axial load of $940 \mathrm{kN}$ was applied to the wall from four $600-\mathrm{kN}$-capacity hydraulic jacks. The simulated lateral earthquake load was applied through the top slab by two $1000-\mathrm{kN}$-capacity horizontal actuators.

A finite element analysis was carried out on the specimen. The specimen was modeled by the finite element mesh, as shown in Figure 14. This mesh size was chosen to ensure the wall zones with different amounts of steel were defined correctly. The web wall and each flange wall were modeled by 30 CSMMShellS8 elements each. Five layers of concrete and two layers of reinforcement were assigned for each element using the CSMMLayer material module. The steel layers were defined at the exact locations of reinforcement of the cross-section of each element. The amount of reinforcement used in each element was defined equivalently to each region of the wall given in Table 5. As shown in Figure 14, the top slab of the specimen was modeled by 30 RigidShellS8 elements, which were elastic 8-node shell elements with high stiffness. All nodes at the bottom of the model were constrained to not allow any translations and rotations to simulate the rigid foundation. Uniformly distributed loads were applied horizontally at all nodes along the two edges of the top slab to simulate the load applied from horizontal actuators. The analysis was performed by a predetermined displacement control scheme. The common displacement increment used 
in the analysis was $0.5 \mathrm{~mm}$. The KrylovNewton method was used as the solution algorithm. The nodal displacement and corresponding horizontal forces were recorded at each converged displacement step, and the stress and strain of the elements were monitored.

The analytical horizontal force versus displacement relationships of the specimen obtained from the analytical model were compared with the experimental results, as shown in Figure 15. The analytical and experimental results are illustrated by a solid curve and a dotted curve, respectively. Table 4 also shows the comparison of the analytical and experimental results regarding the loads and displacements at peak loads of the $\mathrm{RC}$ wall. The analytical results were shown to provide a good correlation with the experimental data. Overall, the primary backbone curve, the initial stiffness, the peak strength, the descending branch and the failure characteristic of the analytical result matched closely with the experimental outcome. Also, the analytical model accurately predicted the unloading path and the pinching effect of the specimen.

\section{CONCLUSIONS}

Following the success of membrane element development for finite element analysis of two-dimensional wall-type structures with OpenSees, a new CSMM-based shell element is developed and implemented into the finite element program SCS-3D using OpenSees as a framework to predict the nonlinear behavior of RC shell-type structures. To validate the developed shell element, several types of RC structures were selected for the analytical models, including RC panels, a RC cylindrical tank and a 3D RC shear wall. Agreements were obtained when analytical results were compared with experimental data. Overall, the 
primary backbone curves, the initial stiffness, the peak strength, the descending branch and the failure characteristics were accurately predicted. The analytical hysteresis loops could provide accurate measurements of the pinching effect, the residual displacement, the ductility and the energy dissipation capacity. Hence, the newly developed CSMM-based shell element could be a powerful and versatile analytical tool for studying the cyclic response of both curved and flat RC shell structures.

\section{ACKNOWLEDGEMENT}

The research described in this paper is financially supported by the U.S. Department of Energy NEUP program (Project No. CFP-13-5282). The opinions expressed in this study are those of the authors and do not necessarily reflect the views of the sponsor

\section{NOTATION}

$$
\begin{array}{ll}
X, Y, Z & =\text { global coordinate of the shell element } \\
x, y, z & =\text { local coordinate of the shell element } \\
\xi, \eta, \zeta & =\text { curvilinear coordinate of the shell element } \\
V_{1 i}, V_{2 i} & =\text { nodal vectors tangential to the middle surface of the shell element } \\
V_{3 i} & =\text { nodal vector perpendicular to the middle surface of the shell element } \\
1-2 & =\text { local coordinate of a steel layer in } \mathrm{t}^{\text {th }} \text { direction } \\
x_{s i}-y_{s i} & =\text { angle between the }(x-y) \text { coordinate system and }(1-2) \text { coordinate system } \\
\theta_{1} & =\text { angle between the }(x-y) \text { coordinate system and }\left(x_{s i}-y_{s i}\right) \text { coordinate system } \\
\theta_{s i} & =\text { the thickness at node } i \text { of the shell element } \\
t_{i} &
\end{array}
$$




$$
\begin{aligned}
& N_{i}(\xi, \eta) \quad=\quad \text { the two-dimension shape function at node } \mathrm{i} \\
& \ell_{k i}, m_{k i}, n_{k i}=\text { the direction cosines of the nodal vector } V_{k i} \\
& u_{X i}, u_{Y i}, u_{Z i}=\text { displacements at node } \mathrm{i} \text { with respect to the global coordinate } \\
& \alpha_{i}, \beta_{i}=\text { rotations at node } \mathrm{i} \text { with respect to the global coordinate } \\
& \sigma_{X}, \sigma_{Y}, \sigma_{Z}=\text { normal stresses in } X-, Y \text {-, and } Z \text { - directions } \\
& \tau_{Y Z}, \tau_{X Z}, \tau_{X Y}=\quad \text { shear stresses in } X \text {-, } Y \text {-, and } Z \text { - directions } \\
& \sigma_{x}, \sigma_{y}, \sigma_{z}=\text { normal stresses in } x-, y \text {-, and } z \text { - directions } \\
& \tau_{y z}, \tau_{x z}, \tau_{x y}=\quad \text { shear stresses in } x \text {-, } y \text {-, and } z \text {-directions } \\
& \varepsilon_{x}, \varepsilon_{y}, \varepsilon_{z}=\text { smeared biaxial normal strains in } x \text {-, } y \text {-, and } z \text {-directions } \\
& \gamma_{y z}, \gamma_{x z}, \gamma_{x y}=\text { smeared biaxial shear strains in } x-, y \text {-, and } z \text {-directions } \\
& \sigma_{1}^{c}, \sigma_{2}^{c}=\text { normal stresses of concrete in 1- and 2- directions } \\
& \varepsilon_{1}, \varepsilon_{2}=\text { smeared biaxial strains in 1- and 2-directions } \\
& \bar{\varepsilon}_{1}, \bar{\varepsilon}_{2} \quad=\quad \text { smeared uniaxial strains in 1- and 2- directions } \\
& N_{x}, N_{y}, N_{x y}=\text { membrane stress resultants } \\
& M_{x}, M_{y}, M_{x y}=\text { bending moment stress resultants } \\
& Q_{x}, Q_{y} \quad=\quad \text { transverse shear stress resultants } \\
& {\left[\mathrm{k}^{e}\right] \quad=\quad \text { element stiffness matrix }} \\
& {[K]=\text { global stiffness matrix }} \\
& \left\{f^{e}\right\} \quad=\quad \text { internal force vector } \\
& \text { [B] = strain-displacement matrix }
\end{aligned}
$$




$$
\begin{aligned}
& {[\mathrm{J}] \quad=\text { Jacobian matrix }} \\
& \text { [D] } \quad=\text { local material matrix } \\
& {\left[\overline{\mathrm{D}}_{i n}\right] \quad=\text { in-plane tangential material matrix }} \\
& {\left[\overline{\mathbf{D}}_{\text {out }}\right]=\text { out-of-plane tangential material matrix }} \\
& {\left[\overline{\mathbf{D}}_{c}\right] \quad=\quad \text { uniaxial tangential matrix of concrete }} \\
& {\left[\overline{\mathbf{D}}_{s i}\right] \quad=\quad \text { uniaxial tangential matrix of embedded rebars }} \\
& {[V] \quad=\quad \mathrm{Hsu} / \text { Zhu matrix }} \\
& \bar{E}_{1}^{c}=\text { concrete tangent uniaxial modulus in the 1-direction } \\
& \bar{E}_{2}^{c}=\text { concrete tangent uniaxial modulus in the 2-direction } \\
& \bar{E}_{s i} \quad=\quad \text { steel tangent modulus of the steel layer in the } \mathrm{i}^{\text {th }} \text { direction } \\
& G_{12}^{c}=\text { shear modulus of concrete in (1-2) coordinate } \\
& \rho_{s i} \quad=\quad \text { reinforcement ratio of the steel layer in the } \mathrm{i}^{\text {th }} \text { direction }
\end{aligned}
$$$$
[T(\alpha)]=\text { transformation matrix }\left[\begin{array}{ccc}
\cos ^{2} \alpha & \sin ^{2} \alpha & 2 \sin \alpha \cos \alpha \\
\sin ^{2} \alpha & \cos ^{2} \alpha & -2 \sin \alpha \cos \alpha \\
-\sin \alpha \cos \alpha & \sin \alpha \cos \alpha & \cos ^{2} \alpha-\sin ^{2} \alpha
\end{array}\right]
$$

\section{REFERENCES}

[1] Ugural AC. Stresses in Beams, Plates, and Shells: CRC Press; 2009.

[2] Hand FR, Pecknold DA, Schnobrich WC. A Layered Finite Element Nonlinear Analysis of Reinforced Concrete Plates and Shells: University of Illinois Engineering Experiment Station. College of Engineering. University of Illinois at Urbana-Champaign.; 1972.

[3] Cervera M, Hinton E, Hassan O. Nonlinear Analysis of Reinforced Concrete Plate and Shell Structures using 20-noded Isoparametric Brick Elements. Computers \& structures. 1987;25:845-69.

[4] Scordelis AC, Chan EC. Nonlinear Analysis of Reinforced Concrete Shells. ACI Special Publication. 1987;98.

[5] Hu HT, Schnobrich WC. Nonlinear Finite Element Analysis of Reinforced Concrete 
Plates and Shells under Monotonic Loading. Computers \& Structures. 1991;38:637-51.

[6] Polak MA, Vecchio FJ. Reinforced Concrete Shell Elements Subjected to Bending and Membrane Loads. ACI Structural Journal-American Concrete Institute. 1994;91:261-8.

[7] Kim TH, Lee KM, Shin HM. Nonlinear Analysis of Reinforced Concrete Shells using Layered Elements with Drilling Degree of Freedom. ACI Structural Journal. 2002;99.

[8] Zhang YX, Bradford MA, Gilbert RI. A Layered Cylindrical Quadrilateral Shell Element for Nonlinear Analysis of RC Plate Structures. Advances in Engineering Software. 2007;38:488-500.

[9] Lee HP. Shell Finite Element of Reinforced Concrete for Internal Pressure Analysis of Nuclear Containment Building. Nuclear Engineering and Design. 2011;241:515-25.

[10] Xiang HJ, Mo YL, Hsu TTC. Seismic Simulation of RC Wall-type Structures using Softened Shell Model. 2012.

[11] Gopinath S, Iyer N, Rajasankar J, D'Souza S. Nonlinear Analysis of RC Shell Structures using Multilevel Modelling Techniques. Engineering Computations. 2012;29:104-24.

[12] Matešan D, Radnić J, Baloević G, Smilović M. Nonlinear Analysis of Concrete Shells Including Effects of Normal and Transverse Shear Stresses. Materialwissenschaft und Werkstofftechnik. 2014;45:258-68.

[13] Hrynyk TD, Vecchio FJ. Capturing Out-of-plane Shear Failures in the Analysis of Reinforced Concrete Shells. Journal of Structural Engineering. 2015;141.

[14] Lu X, Xie L, Guan H, Huang Y, Lu X. A Shear Wall Element for Nonlinear Seismic Analysis of Super-Tall Buildings Using OpenSees. Finite Elements in Analysis and Design. 2015;98:14-25.

[15] Hsu TTC, Mo YL. Unified Theory of Concrete Structures: John Wiley \& Sons; 2010.

[16] Collins MP, Vecchio F. The Response of Reinforced Concrete to In-plane Shear and Normal Stresses. University of Toronto. 1982.

[17] Hsu TTC, Belarbi A, Xiaobo P. A Universal Panel Tester. Journal of Testing and Evaluation. 1995;23:41-9.

[18] Vecchio F, Collins MP. Stress-Strain Characteristics of Reinforced Concrete in Pure Shear. Reports of the Working Commissions, International Association for Bridge and Structural Engineering. 1981;34:211-25.

[19] Vecchio FJ. Disturbed Stress Field Model for Reinforced Concrete: Formulation. Journal of Structural Engineering. 2000;126:1070-7.

[20] Belarbi A, Hsu TTC. Constitutive Laws of Softened Concrete in Biaxial Tension Compression. ACI Structural Journal. 1995;92:562-73.

[21] Pang XB, Hsu TTC. Behavior of Reinforced Concrete Membrane Elements in Shear. ACI Structural Journal. 1995;92:665-79.

[22] Pang XB, Hsu TTC. Fixed-Angle Softened-Truss Model for Reinforced Concrete. ACI Structural Journal. 1996;93:197-207.

[23] Hsu TTC, Zhu RRH. Softened Membrane Model for Reinforced Concrete Elements in Shear. ACI Structural Journal. 2002;99:460-9.

[24] Mansour M, Hsu TTC. Behavior of Reinforced Concrete Elements under Cyclic Shear. II: Theoretical Model. Journal of Structural Engineering, ASCE. 2005b;131:54-65. 
[25] Sawab J, Luu CH, Nie X, Lim I, Mo YL, Li M. Structural Integrity of Steel Plate Ultra High-performance Concrete Modules. Journal of Structural Integrity and Maintenance. 2016;1:95-106.

[26] Mo YL, Zhong J, Hsu TTC. Seismic Simulation of RC Wall-type Structures. Engineering Structures. 2008;30:3167-75.

[27] Ahmad S, Irons BM, Zienkiewicz OC. Analysis of Thick and Thin Shell Structures by Curved Finite Elements. International Journal for Numerical Methods in Engineering. 1970;2:419-51.

[28] Hinton E, Owen DRJ. Finite Element Software for Plates and Shells: Pineridge Press Swansea, UK; 1984.

[29] Cook RD. Concepts and Applications of Finite Element Analysis: Wiley. com; 2002.

[30] Luu CH. Development of CSMM-Based Shell Element for Reinforced Concrete Structures: University of Houston; 2016.

[31] Zhong J. Model-Based Simulation of Reinforced Concrete Plane Stress Structures: University of Houston, Houston; 2005.

[32] Maekawa K, Okamura H, Pimanmas A. Non-linear Mechanics of Reinforced Concrete: CRC Press; 2003.

[33] Carlson NN, Miller K. Design and Application of A Gradient-weighted Moving Finite Element Code I: in One Dimension. SIAM Journal of Science Computing. 1998;19:728-65.

[34] OpenSees. Annual Workshop on Open System for Earthquake Engineering Simulation: Pacific Earthquake Engineering Research Center, UC Berkeley; 2013.

[35] Palermo D, Vecchio FJ. Behavior of Three-dimensional Reinforced Concrete Shear Walls. ACI Structural Journal. 2002;99.

[36] Harada M, Onituka S, Adachi M, Matsuo T. Experimental Study on Deformation Performance of Cylindrical Reinforced Concrete Structure. Proc of JCI. 2001;23:1129-34. 


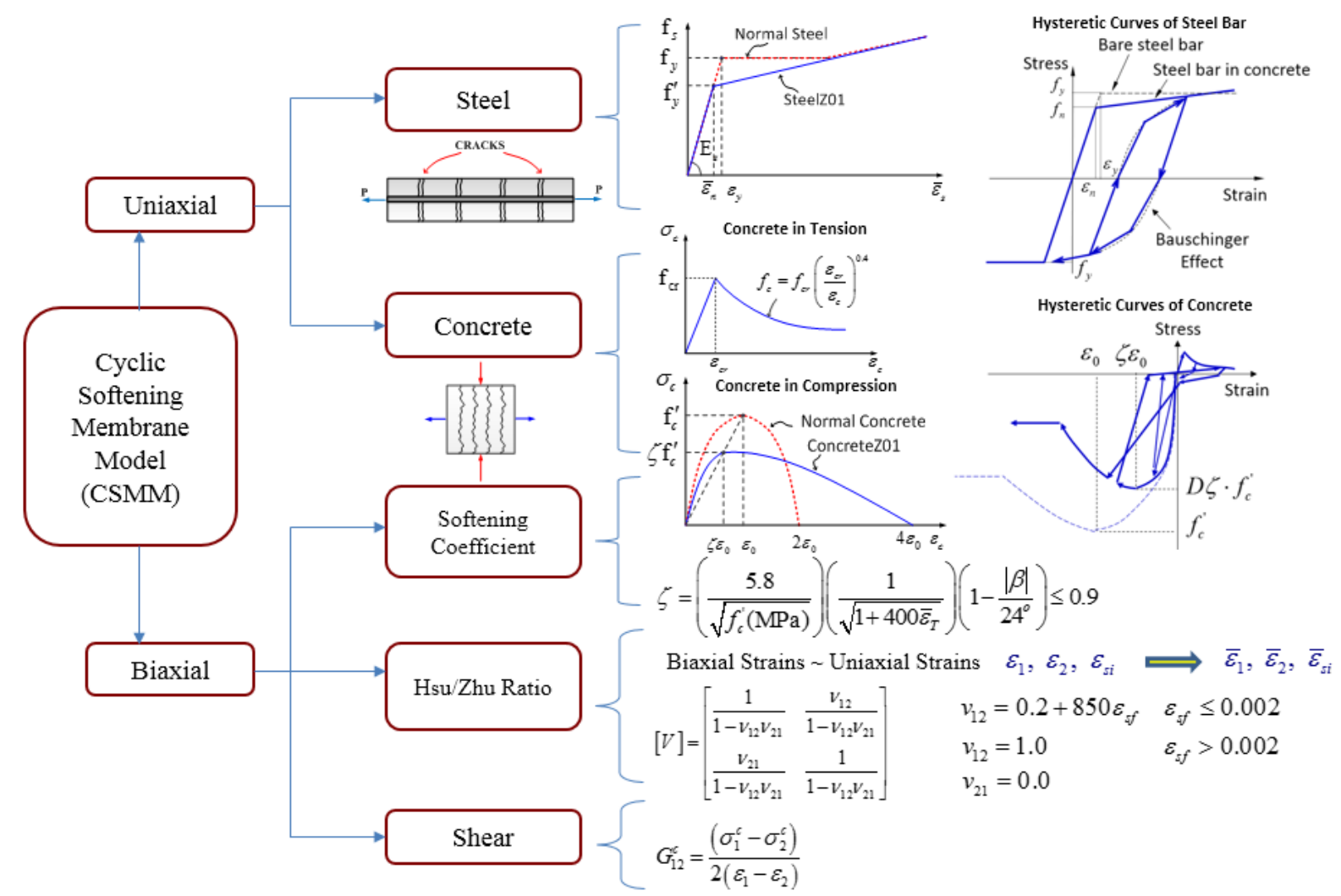

Figure 1 Overview of Cyclic Softening Membrane Model for Reinforced Concrete

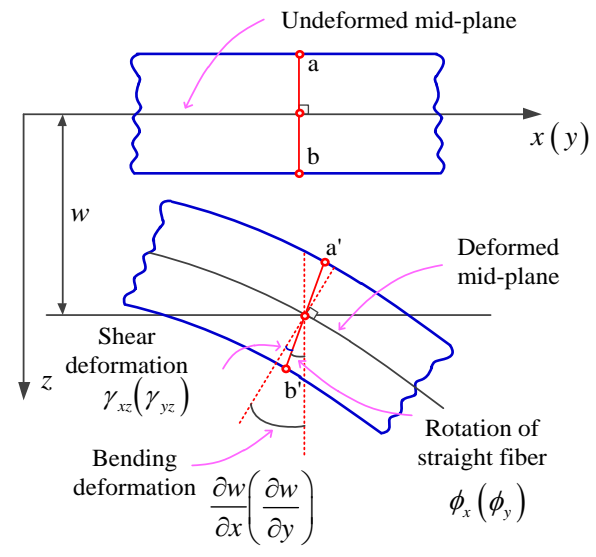

Figure 2 Mindlin theory assumption for the shell element 


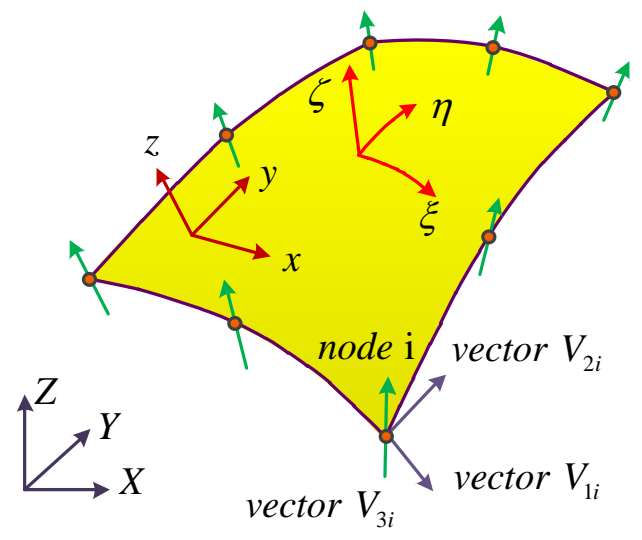

Figure 3 Eight-node degenerated shell element

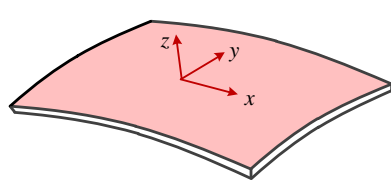

Concrete Layer

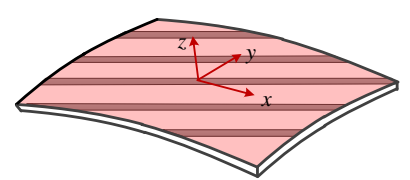

Steel Layer
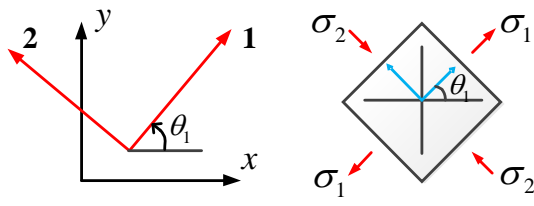

1-2: Orientation of Principal Stress

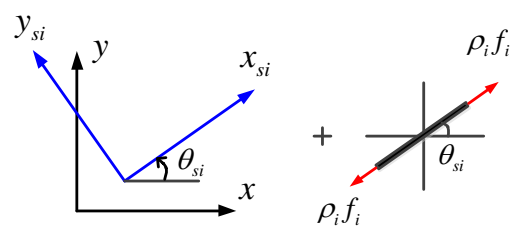

1-2: Orientation of Principal Stress

Figure 4 Coordinate systems for CSMM

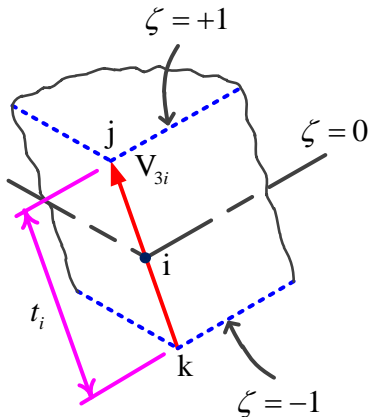

(a)

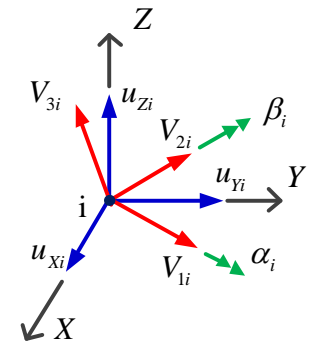

(b)

Figure 5 (a) Typical node i, and thickness-direction vector $V_{3 \mathrm{i}}$ b) Orthogonal vectors at node $i$ and nodal DOF 


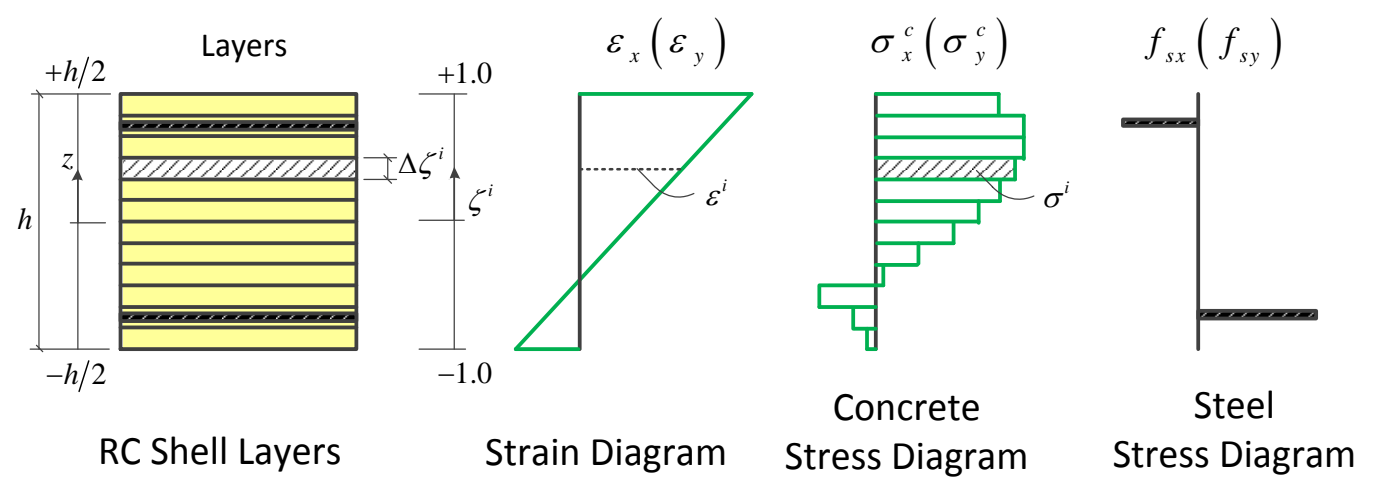

Figure 6 The concept of layered approach

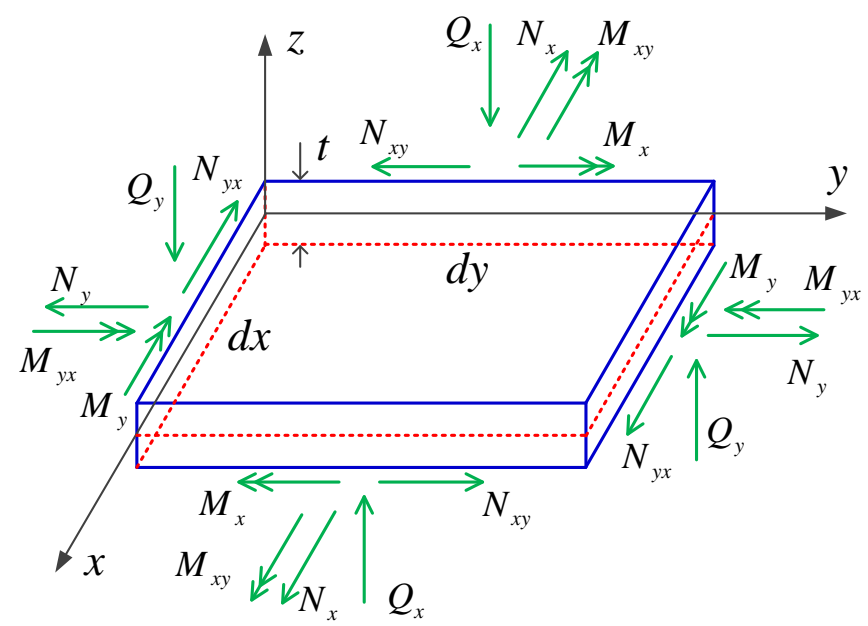

Figure 7 Sign convention for the stress resultants 


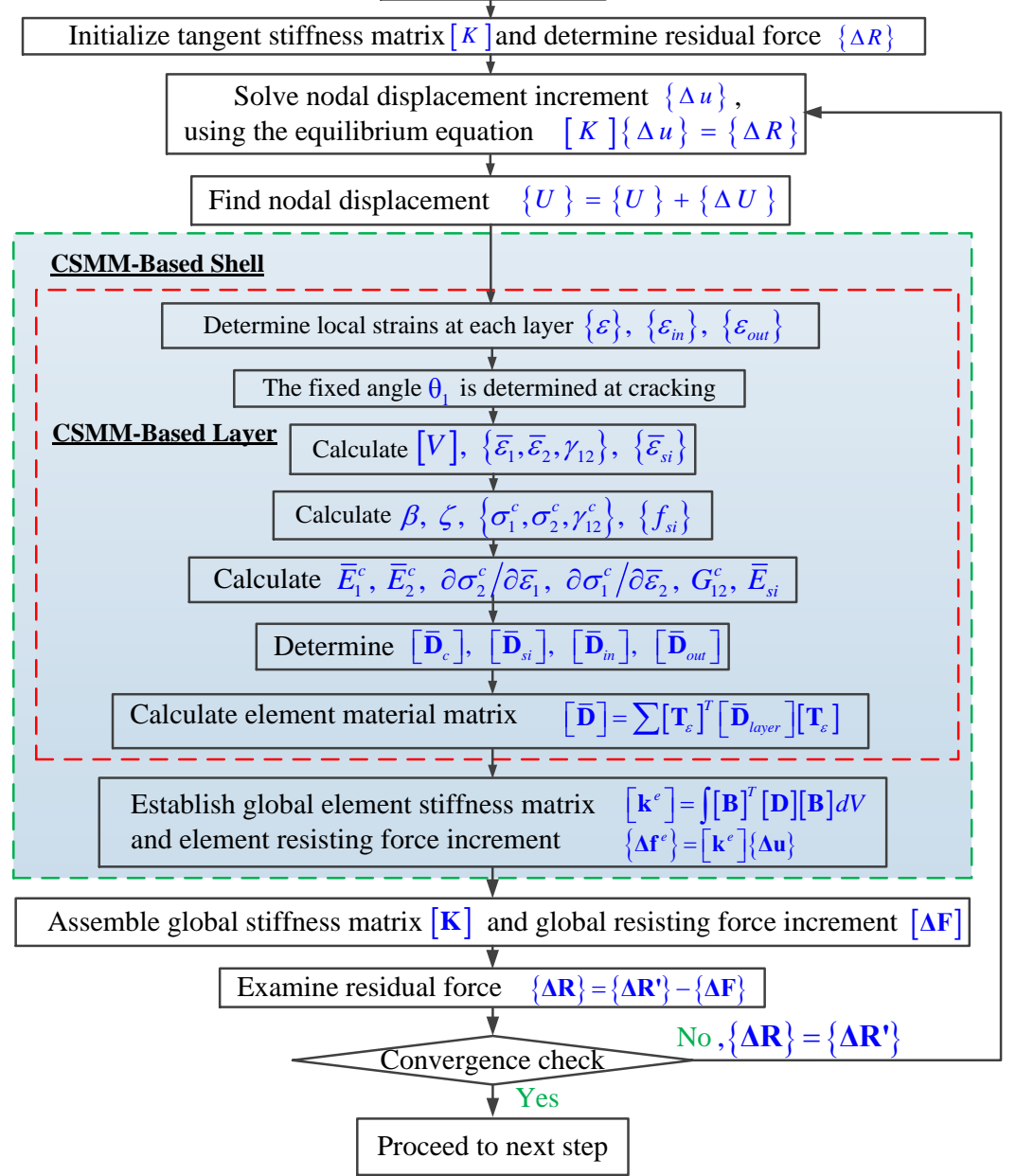

Figure 8 Analysis procedure for the CSMM-based shell element

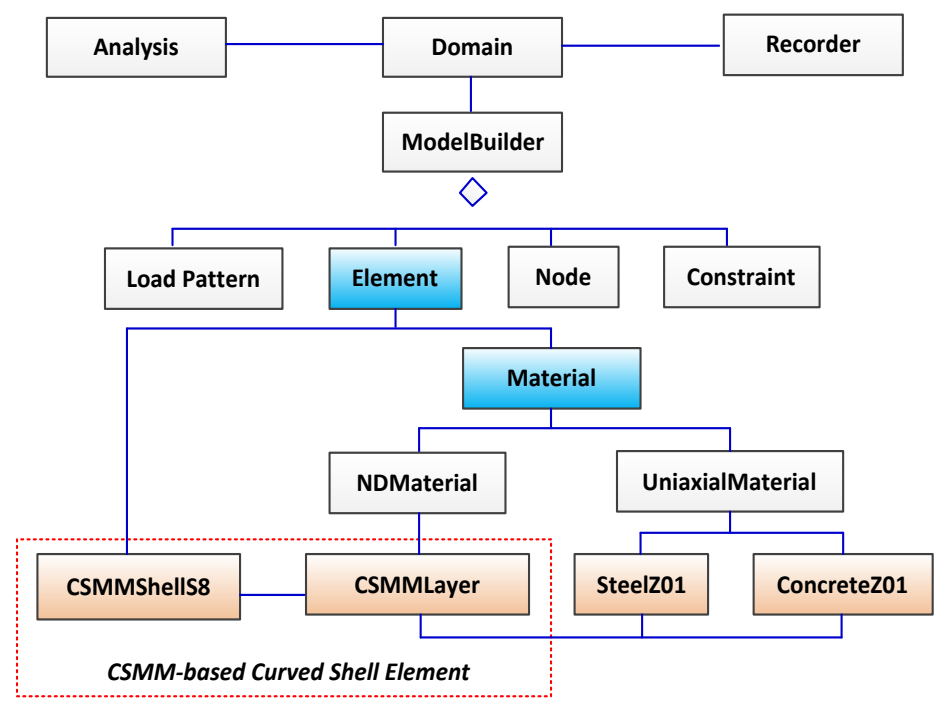

Figure 9 Implementation of the proposed model in OpenSees 


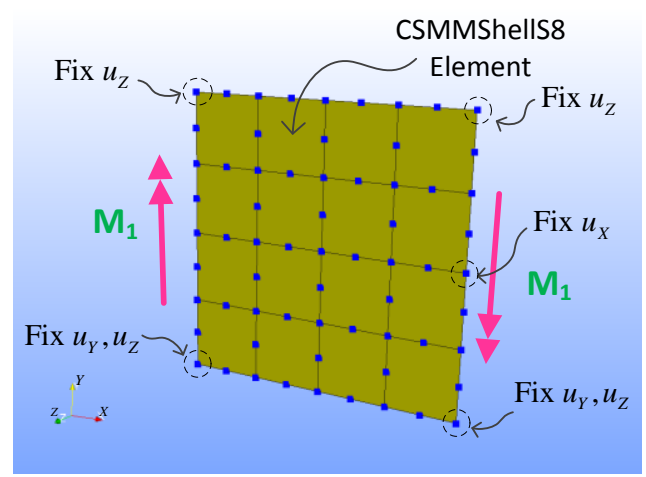

Panel SM1

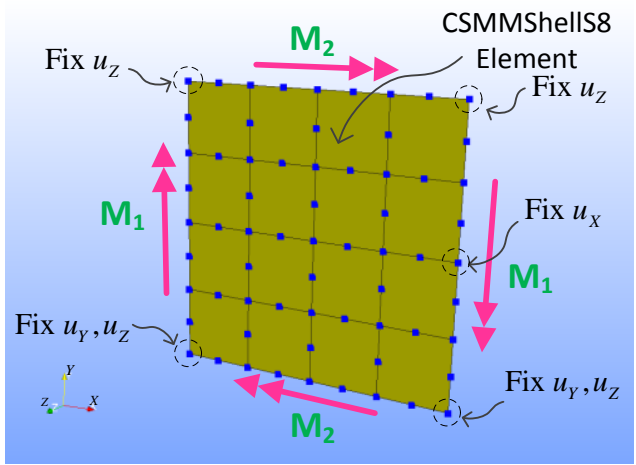

Panel SM3

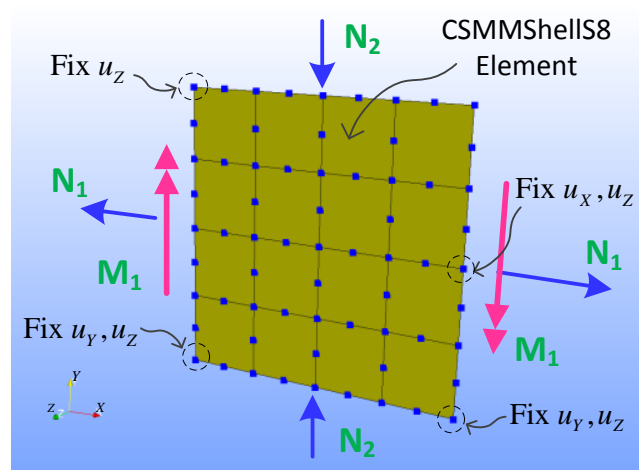

Panel SM2, SM4

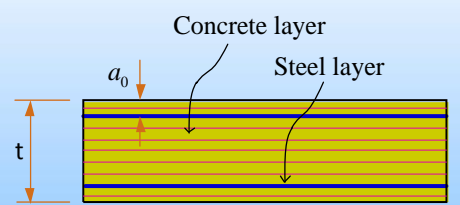

Cross-section mesh

Figure 10 Finite element models of Polak's panels

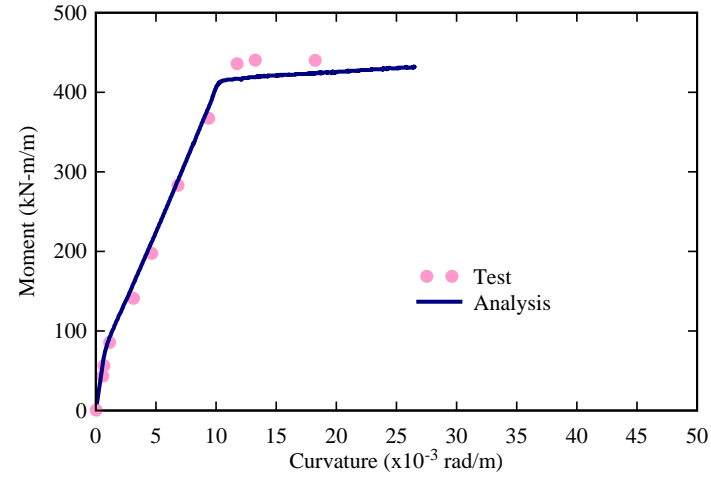

Panel SM1

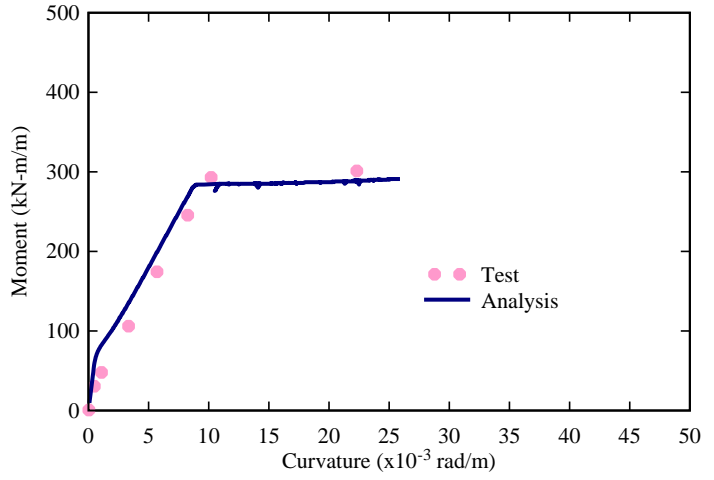

Panel SM2 


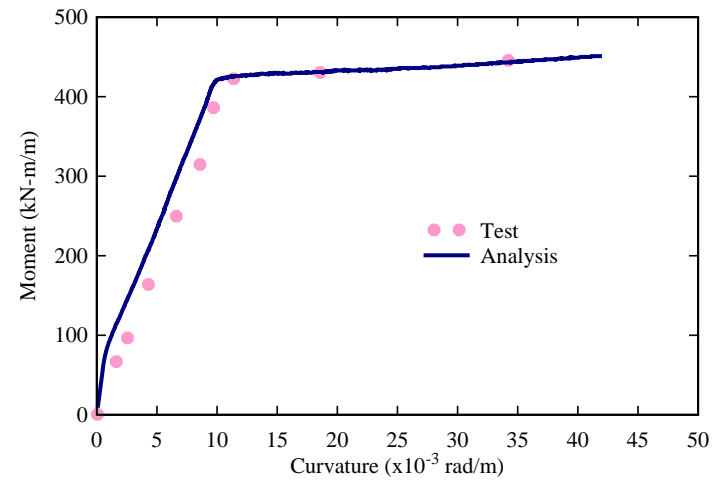

Panel SM3

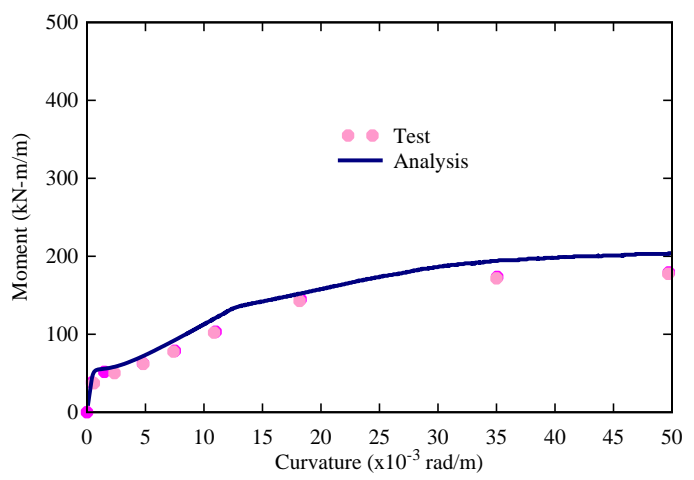

Panel SM4

Figure 11 Comparison between experimental and analytical results for Polak's panels

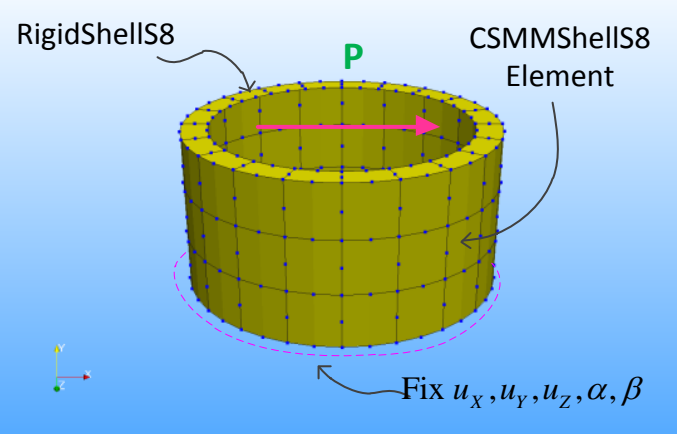

Figure 12 Finite element model of RC cylindrical tank

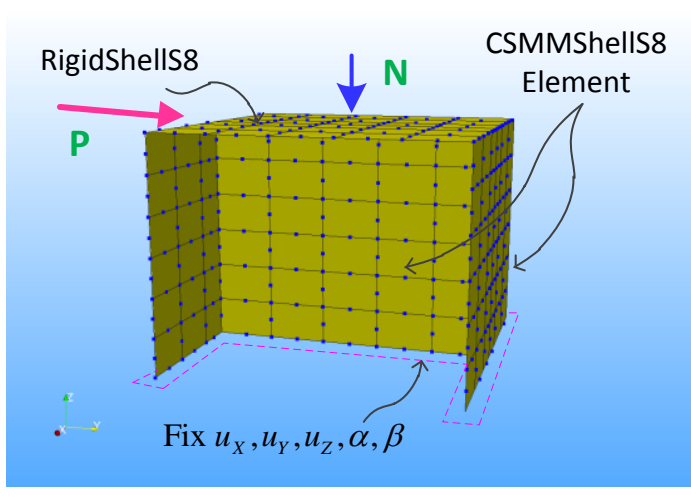

Figure 14 Finite element model of 3D RC shear wall

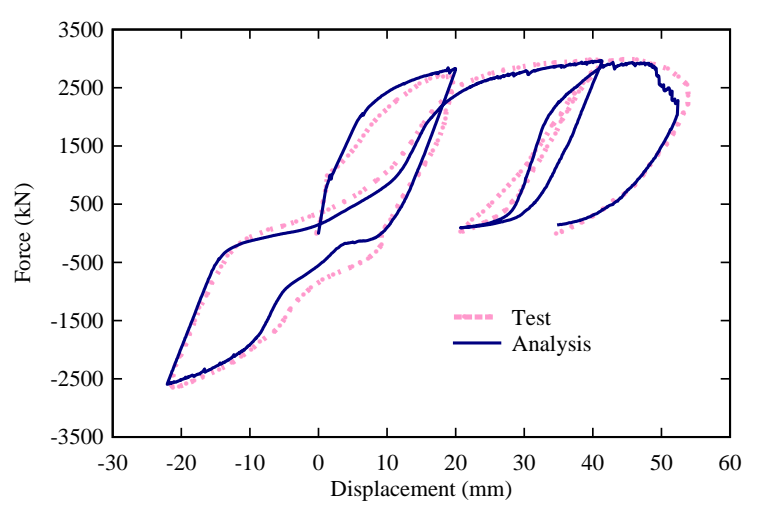

Figure 13 Comparison between experimental and analytical results for $\mathrm{RC}$ cylindrical tank

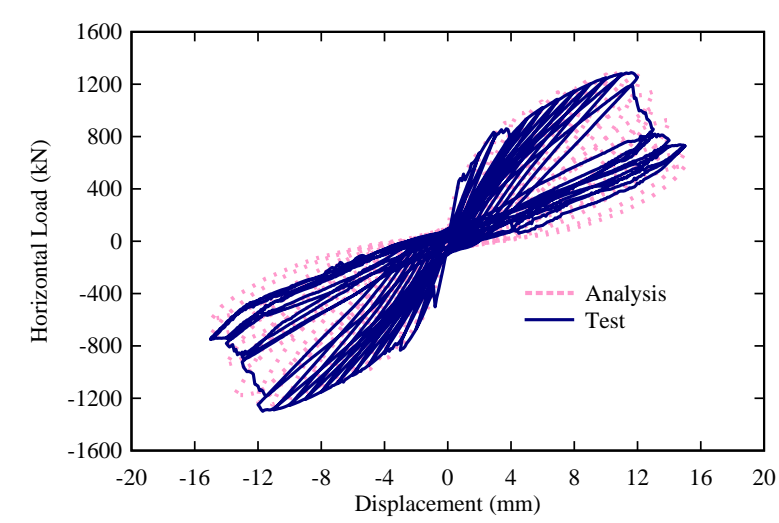

Figure 15 Comparison between experimental and analytical results for 3D RC shear wall 
Table 1 Loading and Material Properties of Polak's Panels

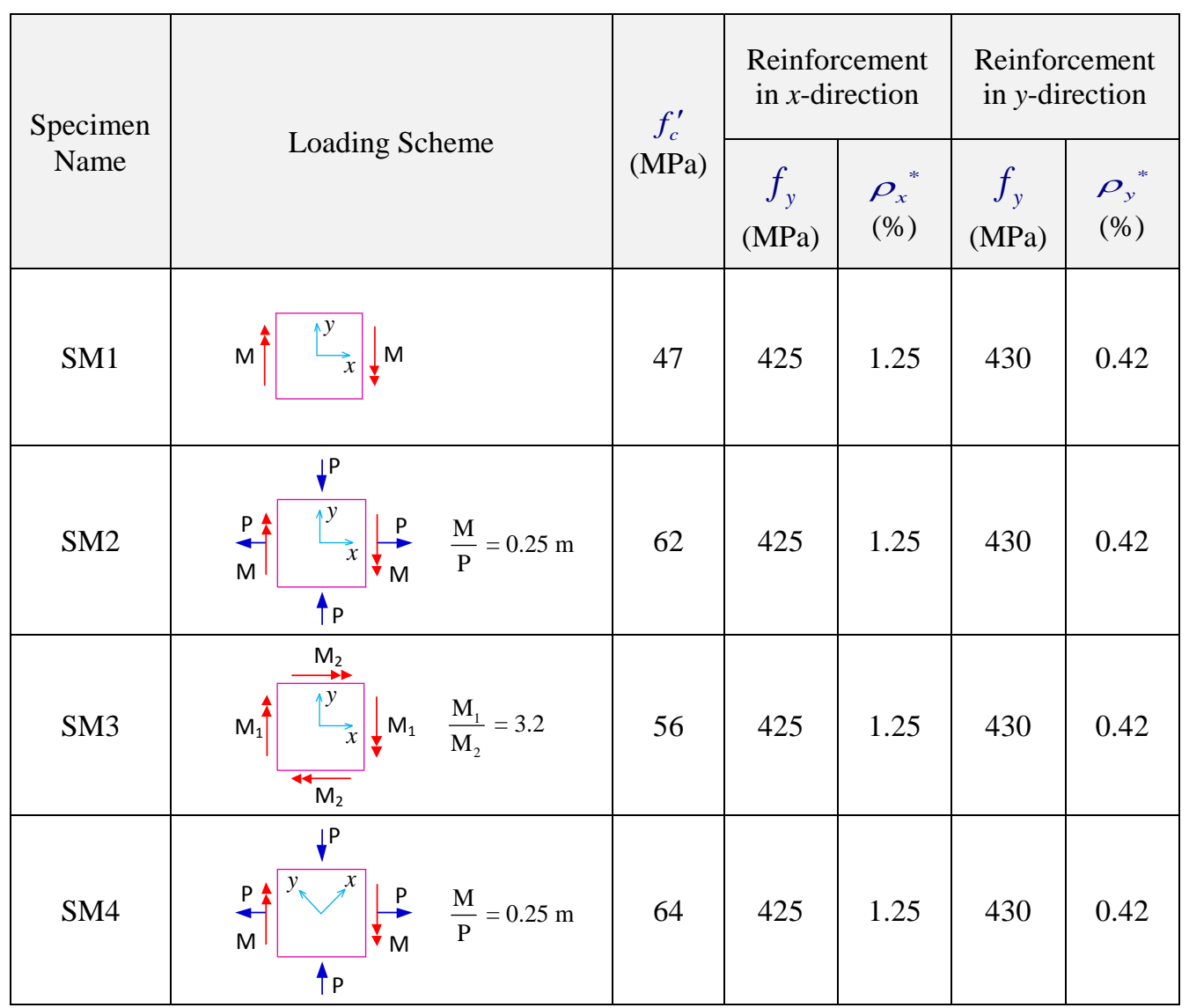

Note * Percentage of reinforcement of each layer at top and bottom of the panel

Table 2 Comparison of test and analysis outcomes of $\mathrm{RC}$ panels

\begin{tabular}{|c|c|c|c|c|c|c|c|c|c|}
\hline \multirow{2}{*}{ Specimen } & \multicolumn{3}{|c|}{ Test } & \multicolumn{3}{c|}{ Analysis } & \multicolumn{3}{|c|}{ Test/Analysis Ratio } \\
\cline { 2 - 10 } & $\begin{array}{c}\mathrm{M}_{\mathrm{cr}} \\
(\mathrm{kN}-\mathrm{m})\end{array}$ & $\begin{array}{c}\mathrm{M}_{\mathrm{y}} \\
(\mathrm{kN}-\mathrm{m})\end{array}$ & $\begin{array}{c}\mathrm{M}_{\mathrm{u}} \\
(\mathrm{kN}-\mathrm{m})\end{array}$ & $\begin{array}{c}\mathrm{M}_{\mathrm{cr}} \\
(\mathrm{kN}-\mathrm{m})\end{array}$ & $\begin{array}{c}\mathrm{M}_{\mathrm{y}} \\
(\mathrm{kN}-\mathrm{m})\end{array}$ & $\begin{array}{c}\mathrm{M}_{\mathrm{u}} \\
(\mathrm{kN}-\mathrm{m})\end{array}$ & $\mathrm{M}_{\mathrm{cr}}$ & $\mathrm{M}_{\mathrm{y}}$ & $\mathrm{M}_{\mathrm{u}}$ \\
\hline SM1 & 75 & 437 & 477 & 72 & 415 & 492 & 1.04 & 1.05 & 0.97 \\
\hline SM2 & 45 & 302 & 421 & 48 & 285 & 408 & 0.94 & 1.06 & 1.03 \\
\hline SM3 & 62 & 435 & 488 & 65 & 423 & 486 & 0.95 & 1.03 & 1.00 \\
\hline SM4 & 51 & 160 & 205 & 49 & 157 & 201 & 1.04 & 1.02 & 1.02 \\
\hline \multicolumn{10}{|c|}{} \\
\hline
\end{tabular}




\begin{tabular}{|c|c|c|c|c|c|c|c|c|}
\hline \multirow{2}{*}{$\begin{array}{l}\text { Specimen } \\
\text { Name }\end{array}$} & \multirow{2}{*}{$\begin{array}{c}f_{c}^{\prime} \\
(\mathrm{MPa})\end{array}$} & \multirow{2}{*}{$\underset{(\mathrm{mm})}{D}$} & \multirow{2}{*}{$\begin{array}{c}H \\
(\mathrm{~mm})\end{array}$} & \multirow{2}{*}{$\begin{array}{c}t \\
(\mathrm{~mm})\end{array}$} & \multicolumn{2}{|c|}{$\begin{array}{l}\text { Reinforcement } \\
\text { in } l \text {-direction }\end{array}$} & \multicolumn{2}{|c|}{$\begin{array}{l}\text { Reinforcement } \\
\text { in } t \text {-direction }\end{array}$} \\
\hline & & & & & $\begin{array}{c}f_{y} \\
(\mathrm{MPa})\end{array}$ & $\begin{array}{l}\rho_{v} \\
(\%)\end{array}$ & $\begin{array}{c}f_{y} \\
(\mathrm{MPa})\end{array}$ & $\begin{array}{l}\rho_{c} \\
(\%)\end{array}$ \\
\hline 1 & 28.0 & 3600 & 2000 & 100 & 384 & 0.8 & 410 & 0.8 \\
\hline
\end{tabular}

Note : $f_{c}^{\prime}=$ Compressive strength of concrete; $D=$ Diameter of the tank; $t=$ Thickness; $f_{y}=$ Yielding strength of steel; $H=$ Effective height of the tank; $\rho_{v}=$ Percentage of the vertical steel; $\rho_{c}=$ Percentage of the circumferential steel.

Table 4 Comparison of test and analysis outcomes of RC tank and 3D wall

\begin{tabular}{|c|c|c|c|c|c|c|c|c|c|c|c|c|}
\hline \multirow[b]{2}{*}{ Specimen } & \multicolumn{4}{|c|}{ Test } & \multicolumn{4}{|c|}{ Analysis } & \multicolumn{4}{|c|}{ Test/Analysis Ratio } \\
\hline & $\begin{array}{l}\Delta_{\max }^{(+)} \\
(\mathrm{mm})\end{array}$ & $\begin{array}{l}\mathrm{V}_{\text {max }}^{(+)} \\
(\mathrm{kN})\end{array}$ & $\begin{array}{l}\Delta_{\text {max }}^{(-)} \\
(\mathrm{mm})\end{array}$ & $\mathrm{V}_{\text {max }}^{(-)}$ & $\begin{array}{l}\Delta_{\text {max }}^{(+)} \\
(\mathrm{mm})\end{array}$ & $\mathrm{V}_{\max }^{(+)}$ & $\begin{array}{l}\Delta_{\max }^{(-)} \\
(\mathrm{mm})\end{array}$ & $\begin{array}{l}\mathrm{V}_{\max }^{(-)} \\
(\mathrm{kN})\end{array}$ & $\Delta_{\max }^{(+)}$ & $V_{\max }^{(+)}$ & $\Delta_{\text {max }}^{(-)}$ & $\mathrm{V}_{\max }^{(-)}$ \\
\hline RC Tank & 44 & 2984 & 21 & 2644 & 41 & 2965 & 22 & 2595 & 1.07 & 1.01 & 0.95 & 1.02 \\
\hline RC Wall & 11 & 1296 & 11 & 1248 & 11.6 & 1288 & 11.7 & 1299 & 0.95 & 1.01 & 0.94 & 0.96 \\
\hline
\end{tabular}
direction, respectively; $\mathrm{V}_{\max }^{(-)}, \Delta_{\max }^{(-)}=$Peak horiozontal load and the corresponding displacement in the negative direction, respectively.

Table 5 Dimension and Material Properties of the 3D Shear Wall

\begin{tabular}{|c|c|c|c|c|c|c|c|c|}
\hline \multirow{2}{*}{ Wall Zone } & \multirow{2}{*}{$\begin{array}{c}f_{c}^{\prime} \\
(\mathrm{MPa})\end{array}$} & \multirow{2}{*}{$\begin{array}{c}P \\
(\mathrm{kN})\end{array}$} & \multirow{2}{*}{$\frac{P}{f_{c}^{\prime} A_{g}}$} & \multirow{2}{*}{$\underset{(\mathrm{mm})}{L}$} & \multicolumn{2}{|c|}{$\begin{array}{l}\text { Longitudinal } \\
\text { reinforcement }\end{array}$} & \multicolumn{2}{|c|}{$\begin{array}{l}\text { Transverse } \\
\text { reinforcement }\end{array}$} \\
\hline & & & & & $\begin{array}{c}f_{y} \\
(\mathrm{MPa})\end{array}$ & $\begin{array}{c}\rho_{l} \\
(\%)\end{array}$ & $\begin{array}{c}f_{y} \\
(\mathrm{MPa})\end{array}$ & $\begin{array}{l}\rho_{t} \\
(\%)\end{array}$ \\
\hline Web & \multirow{3}{*}{21.7} & \multirow{3}{*}{940} & \multirow{3}{*}{0.054} & \multirow{3}{*}{2020} & \multirow{3}{*}{605} & 0.8 & \multirow{3}{*}{605} & 0.73 \\
\hline Inner Flange & & & & & & 0.62 & & 0.58 \\
\hline Outer Flange & & & & & & 0.23 & & 0.58 \\
\hline
\end{tabular}

Note : $f_{c}^{\prime}=$ Compressive strength of concrete; $A_{g}=$ Area of cross section; $f_{y}=$ Yielding strength of steel; $L=$ Effective height of the wall; $\rho_{l}=$ Percentage of the longitudinal steel; $\rho_{t}=$ Percentage of the transverse steel. 